\begin{tabular}{c}
\hline$J C E B T, 5(1)$ Maret 2021 ISSN 2549-6379 (Print) ISSN 2549-6387 (Online) \\
JCEBT \\
ONournal of Civil Engineering, Building and Transportation) \\
Available online http://ojs.uma.ac.id/index.php/jcebt \\
\hline
\end{tabular}

\title{
Analisis Kekuatan Geser Pada Hubungan Balok-Kolom Interior Beton Bertulang
}

\section{Analysis of Shear Strength in Relationships Reinforced Concrete Interior Columns}

\author{
Sudarno P. Tampubolon \\ Prodi Sipil, Fakultas Teknik \\ Universitas Kristen Indonesia, Indonesia
}

*Coresponding Email: darno_tampubolon@yahoo.com

\begin{abstract}
Abstrak
Pertemuan antara balok-kolom pada beton bertulang merupakan bagian dari struktur yang sangat kritis bila terjadi gempa bumi. Hal ini dapat terjadi karena balok-kolom menerima gaya geser yang besar dan sering tidak diberi pendetailan yang baik. Studi analisa ini akan membahas nilai dari kekuatan geser horizontal dari sebelas spesimen pada pertemuan balok-kolom interior dengan mempergunakan metode Softened Strut-and-Tie dan ACI, lalu membandingkannya dengan hasil uji laboratorium yang tersedia di literatur untuk mengetahui keakuratan dari metode yang dipergunakan dalam menentukan nilai dari kekuatan geser. Dari analisa dan verifikasi terhadap sebelas spesimen, metode Softened Strut-and-Tie memberikan hasil yang lebih baik dan mendekati hasil uji laboratorium dibandingkan dengan metode ACI.
\end{abstract}

Kata Kunci: Pertemuan balok-kolom interior, beton bertulang, Softened Strut-and-Tie, kekuatan geser.

\begin{abstract}
Beam-column joints in reinforced concrete structures are very critical part when an earthquake occur. It is happened since the beam-column receives a large shear forces and are often not given a good detailing. This analysis discussed about the value of the horizontal shear strength of the eleven specimen beamcolumn joints interior by using the method of Softened Strut-and-Tie and ACI, then compared with laboratory test results that are available in the literature. The purpose is to determine the accuracy of the method that used in determining values of shear strength. From the analysis and verification of the eleven specimens, Softened Strut-and-Tie method provides results close to laboratory test results compared with the ACI method.
\end{abstract}

Keywords: Interior beam-column joints, reinforced concrete, Softened Strut-and-Tie, shear strength.

How to Cite: Sudarno P. Tampubolon (2020). Analisis Kekuatan Geser Pada Hubungan Balok-Kolom Interior Beton bertulang. JCEBT (Journal of Civil Engineering, Building and Transportation). 5 (1): 56-63 


\section{PENDAHULUAN}

Sambungan balok-kolom (beam-column joint) merupakan bagian yang rawan pada struktur tahan gempa karena sifat pemecaran energinya yang spesifik. Pertemuan balok-kolom pada sebuah portal beton bertulang merupakan bagian yang kritis saat terjadi bencana gempa. Keruntuhan yang terjadi pada saat terjadi gempa kebanyakan merupakan keruntuhan geser. Umumnya kegagalan struktur akibat gempa terjadi di pertemuan balok-kolom (beam-column joint). Pada saat terjadi gempa, daerah pertemuan mengalami gaya momen dan geser yang lebih besar dibandingkan dengan daerah lain pada balok maupun kolom. Oleh sebab itu pertemuan balokkolom merupakan daerah yang kritis dan sering mengalami kegagalan struktur. Strut-and-Tie Model merupakan salah satu teori yang digunakan untuk memprediksi discontinuity regions atau daerah yang terganggu pada pertemuan balok-kolom beton bertulang.

Selain pada pertemuan balok-kolom, daerah diskontiniutas (D-regions) juga terdapat pada corbel, squat, wall, dan deep beam. Teori Strut-and-Tie Model pertama kali dikemukakan oleh Ritter (1899) dan Morsch (1909). Walaupun teori Strutand-Tie Model dianggap rasional namun hasilnya hanyalah sebuah pendekatan dan dianggap kurang akurat. Dalam teori Strut-and-Tie Model, tegangan ditentukan oleh kondisi kesetimbangannya sendiri, sedangkan persamaan kompatibilitas regangan diabaikan. Tanpa persamaan kompatibilitas regangan, perancang bebas dalam memilih Strut dan Tie yang efisien dan memenuhi keadaan kesetimbangan. Oleh sebab itu dalam beberapa kondisi yang diberikan, banyak model Strut dan Tie yang dapat digunakan sehingga tidak ada solusi yang unik. Selanjutnya teori ini dikembangkan oleh Hwang dan Lee $(1999,2000)$ dan diberi nama teori Softened Strut-and-Tie Model. Teori ini telah memenuhi hukum kesetimbangan, kompatibilitas, dan hukum konstitutif dari beton bertulang yang retak (cracked reinforced concrete). Kekuatan beton yang masih utuh berbeda dengan kekuatan beton yang sudah retak, sehingga dengan memprediksi beton bertulang yang telah retak maka keakuratan prediksi menjadi semakin tinggi.

Teori Softened Strut- and-Tie Model juga memprediksi kekuatan geser pada pertemuan balok-kolom pada daerah diskontinuitas pada beton bertulang. Teori ini merupakan prosedur memprediksi kekuatan beton yang tidak rumit dan berkaitan dengan prediksi geser terhadap kehancuran diagonal pada 
daerah diskontinuitas beton bertulang.

\section{METODE PENELITIAN}

Adapun metodologi penelitian yang dilakukan di dalam penelitian ini adalah secara analisis, dimana penelitian ini akan membahas dua buah metode yang berbeda dalam penentuan kuat geser pada pertemuan balok kolom (interior beamcolumn joint). Adapun metode yang akan dipergunakan adalah metode ACI-318 dan metode Softened Strut-and-Tie (SST) yang baru dikembangkan oleh Hwang dan Lee (1999, 2000). Adapun tujuan dari penelitian yang dilakukan adalah untuk membandingkan dan mengetahui keakuratan dari kedua metode ini dengan hasil uji laboratorium yang dilakukan oleh Oka dan Shiohara, (1992) terhadap kuat geser pada beam-column joints interior. Pertemuan antara balok dengan kolom haruslah dirancang terhadap gaya gempa, supaya bangunan tidak langsung mengalami keruntuhan struktur saat terjadi gempa.

Berdasarkan ACI-318, kuat geser horisontal pada sambungan balok-kolom dibagi dua yaitu tipe-1 (nonseismic) dan tipe-2 (seismic). Dalam penelitian ini hanya menggunakan tipe-2 akibat dari gempa. Gaya geser horisontal nominal $\left(\mathrm{V}_{\mathrm{n}}\right)$ pada pertemuan balok-kolom dapat ditentukan dengan:
$V_{j h, n}^{A C I}=\Upsilon \cdot \frac{\sqrt{f c^{\prime}}}{12} \cdot A_{j}$

Dari hasil tes nilai untuk kuantitas $\gamma$ pada pertemuan antara balok dan kolom dapat diperlihatkan pada gambar 1 dibawah ini:
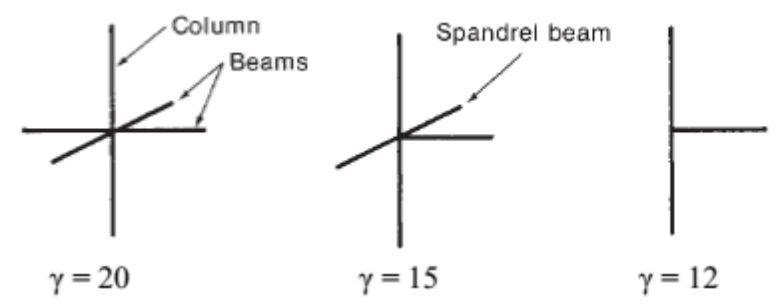

Gambar 1. Klasifikasi nilai $\gamma$ pada pertemuan balok-kolomakibatdarigayagempa (Mac Gregor, 2006)

Luas efektif daerah sambungan $A_{j}=b_{j} x$ $\mathrm{h}_{\mathrm{col}}$, luas efektif sambungan $\mathrm{A}_{\mathrm{j}}$ tidak boleh melebihi luas penampang kolom, dimana $\mathrm{h}_{\text {col }}$ adalah tinggi kolom dan lebar efektif pertemuan $b_{j}$ ditentukan sebagai:

$b_{j}=b_{b}+2 x \leq b_{b}+h_{c o l}$ dengan: $b_{b}=$ lebar balok

$\mathrm{x}=$ jarak terkecil antara muka balok dengan muka kolom yang sejajar dengan gaya geser. 
Adapun langkah-langkah untuk mendapatkan kekuatan geser nominal pada pertemuan balok-kolom interior berdasarkan ACI-318 dapat diperlihatkan pada flowchart dibawah ini:

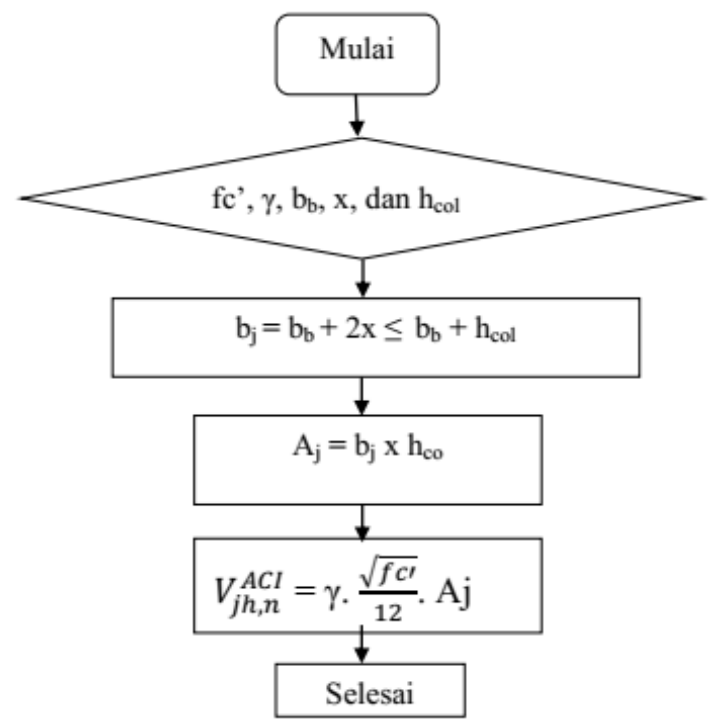

Gambar 2. Flowchart untuk perhitungan kuat geser pada pertemuan balok-kolom dengan metode ACI-318

Dalam hal ini juga akan dijelaskan metode Softened Strut-and-Tie (SST) yang digunakan dalam menentukan kekuatan gaya geser horisontal dimana metode SST mengacu pada konsep strong column-weak beam. Berikut ini akan dijelaskan flowchart perhitungan kekuatan geser nominal pada pertemuan balok-kolom interior dengan metode Softened Strut and Tie (SST).

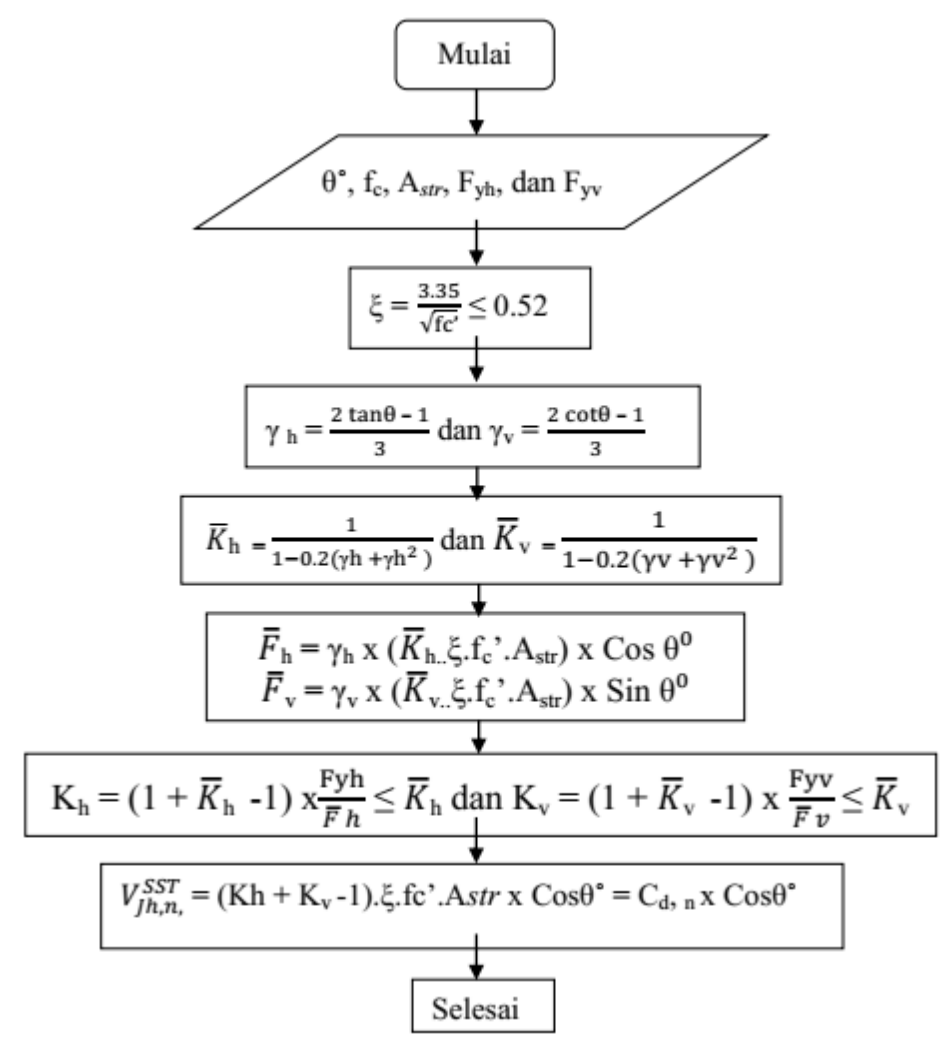

Gambar 3. Flowchart perhitungan kuat geser pada pertemuan balok-kolom dengan metode Softened Strut-and-Tie (SST), (Hwang dan Lee, 1999, 2000)

\section{HASIL DAN PEMBAHASAN}

Penelitian ini akan diuji keakuratan metode ACI-318 dan metode Softened Strut and Tie (SST) untuk hasil pengujian test speciment oleh Oka dan Shiohara, (1992). Gambar 3 merupakan susunan sistem pengujian (test) yang dilakukan terhadap 11 spesimen. Gaya aksial yang diberikan terhadap spesimen juga berbeda, dimana untuk spesimen J-1 sampai J-9 diberikan gaya aksial sebesar $834 \mathrm{kN}$ sedangkan untuk spesimen J-10 sampai J-11 diberikan gaya aksial sebesar 417 kN. Spesimen ini dirancang dengan dimensi kolom (300x300) mm dan untuk 
balok (240x300) mm sedangkan untuk ukuran tulangan kolom dan balok dipergunakan tulangan dengan diameter (D-13), (D-19), dan (U-13) dengan jumlah tulangan balok yang berbeda. Sedangkan untuk tulangan sengkangnya (confinement) dipergunakan tulangan D-6.

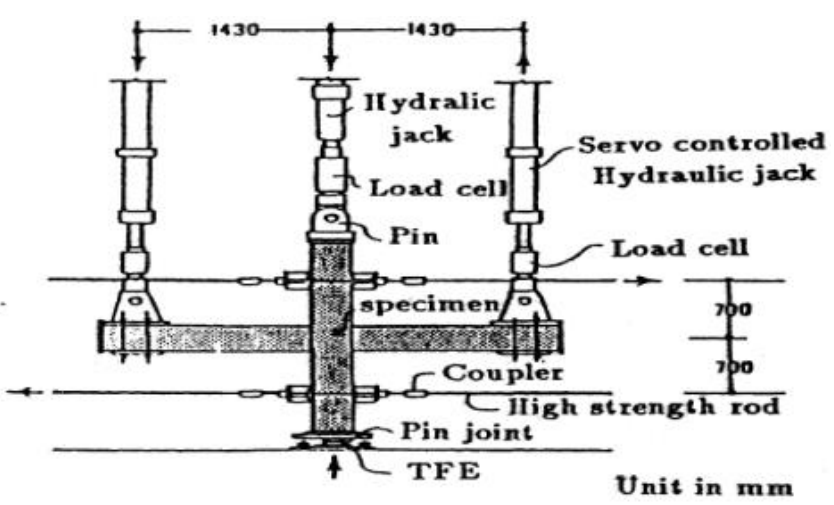

Gambar 4. Susunan pengujian (Oka dan Shiohara, 1992)

Dari hasil pengujian yang telah dilakukan oleh Oka dan Shiohara, (1992) terhadap 11 spesimen, diperoleh tegangan geser yang berbeda untuk setiap spesimen yang telah dibuat. Adapun hasil uji test yang diperoleh untuk tiap spesimen diperlihatkan pada tabel 1 dibawah ini.

Tabel 1. Hasil pengujian (Oka dan Shiohara, 1992)

\begin{tabular}{|c|l|r|r|r|r|r|r|r|r|r|r|}
\hline $\begin{array}{c}\text { Spesime } \\
\text { nt }\end{array}$ & J-1 & J-2 & J-3 & J-4 & J-5 & J-6 & J-7 & J-8 & J-9 & J-10 & J-11 \\
\hline $\begin{array}{c}\text { V jh, test } \\
\text { (KN) }\end{array}$ & 257 & 276 & 286 & 265 & 297 & 274 & 219 & 311 & 294 & 196 & 232 \\
\hline
\end{tabular}

Dari hasil perhitungan terhadap 11 speciment dengan menggunakan metode
ACI-318 dapat diperlihatkan dalam tabel di bawah ini:

Tabel 2. Hasil perhitungan kekuatan geser (joint) horisontal dengan metode ACI-318

\begin{tabular}{|l|c|r|r|c|}
\hline No & $\begin{array}{c}\text { Spesim } \\
\text { en }\end{array}$ & fc' (Mpa) & \multicolumn{1}{|c|}{$\mathrm{A}_{\mathrm{j}}\left(\mathrm{mm}^{2}\right)$} & $V_{j h, n}^{A C I} \quad V_{j h, n,}^{A C I}$, \\
\hline 1 & \multicolumn{1}{|c|}{$\mathrm{J}-1$} & 81,2 & 90000 & 1351,65 \\
\hline 2 & $\mathrm{~J}-2$ & 81,2 & 90000 & 1351,65 \\
\hline 3 & $\mathrm{~J}-3$ & 81,2 & 90000 & 1351,65 \\
\hline 4 & $\mathrm{~J}-4$ & 72,8 & 90000 & 1279,80 \\
\hline 5 & $\mathrm{~J}-5$ & 72,8 & 90000 & 1279,80 \\
\hline 6 & $\mathrm{~J}-6$ & 79,2 & 90000 & 1334,92 \\
\hline 7 & $\mathrm{~J}-7$ & 79,2 & 90000 & 1334,92 \\
\hline 8 & $\mathrm{~J}-8$ & 79,2 & 90000 & 1334,92 \\
\hline 9 & $\mathrm{~J}-9$ & 79,2 & 90000 & 1334,92 \\
\hline 10 & $\mathrm{~J}-10$ & 39,2 & 90000 & 939,14 \\
\hline 11 & $\mathrm{~J}-11$ & 39,2 & 90000 & 939,14 \\
\hline
\end{tabular}

Setelah dilakukan perhitungan dengan menggunakan metode ACI-318 dilakukan juga perhitungan gaya geser dengan menggunakan metode Softened Strut and Tie (SST). Hasil perhitungan yang telah dilakukan deperlihatkan seperti tabel di bawah ini: 
Tabel 3. Hasil perhitungan kekuatan geser (joint) horisontal dengan metode SST

\begin{tabular}{|c|c|c|c|c|c|c|c|c|}
\hline No & $\begin{array}{c}\text { Sp } \\
\text { es } \\
\text { i } \\
\text { m } \\
\text { en }\end{array}$ & $\begin{array}{c}\mathrm{fc}^{\prime} \\
\text { (Mpa } \\
\text { ) }\end{array}$ & $\theta$ & $\begin{array}{c}\text { Astr } \\
\left(\mathrm{mm}^{2}\right)\end{array}$ & $\zeta$ & $\mathbf{K}_{\mathbf{h}}$ & Kv & $V_{J h, n}^{S S T}$ \\
\hline 1 & $\mathrm{~J}-1$ & 81,2 & 53,13 & 31230,3 & 0,37 & 0,34 & 1,04 & 217,78 \\
\hline 2 & $\mathrm{~J}-2$ & 81,2 & 53,13 & 31230,3 & 0,37 & 0,78 & 1,04 & 467,44 \\
\hline 3 & $\mathrm{~J}-3$ & 81,2 & 53,13 & 31230,3 & 0,37 & 0,78 & 1,04 & 467,44 \\
\hline 4 & $J-4$ & 72,8 & 53,13 & 32237,6 & 0,39 & 0,30 & 1,04 & 178,52 \\
\hline 5 & $J-5$ & 72,8 & 53,13 & 32237,6 & 0,39 & 0,49 & 1,04 & 277,41 \\
\hline 6 & $J-6$ & 79,2 & 53,13 & 31450,8 & 0,38 & 0,37 & 1,04 & 228,97 \\
\hline 7 & $\mathrm{~J}-7$ & 79,2 & 53,13 & 31450,8 & 0,38 & 0,37 & 1,04 & 228,97 \\
\hline 8 & $J-8$ & 79,2 & 53,13 & 31450,8 & 0,38 & 0,20 & 1,04 & 135,57 \\
\hline 9 & $J-9$ & 79,2 & 53,13 & 31450,8 & 0,38 & 0,37 & 1,04 & 228,97 \\
\hline 10 & $\begin{array}{l}\mathrm{J}- \\
10\end{array}$ & 39,2 & 53,13 & 31542,1 & 0,52 & 0,55 & 1,04 & 229,26 \\
\hline 11 & $\begin{array}{l}\mathrm{J}- \\
11\end{array}$ & 39,2 & 53,13 & 31542,1 & 0,52 & 0,49 & 1,04 & 204,84 \\
\hline
\end{tabular}

Dari hasil perhitungan yang telah dilakukan dengan menggunakan metode SST dan ACI-318 maka akan diperoleh rasio perbandingan dengan hasil uji laboratorium. Tabel $4 . \quad$ akan memperlihatkan rasio perbandingan antara hasil uji laboratorium dengan metode SST dan ACI-318
Tabel 4. Rasio perbandingan hasil uji lab dengan metode ACI-318 dan metode SST

\begin{tabular}{|c|c|c|c|c|c|c|}
\hline No & $\begin{array}{c}\text { Spesi } \\
\text { men }\end{array}$ & $V_{J h, n,}^{S S T}$ & $V_{j h, t e s t}$ & $V_{J h, n,}^{A C I}$ & $\frac{V_{j h, t e s t}}{V_{J h, n}^{S S T}}$ & $\frac{V_{j h, t e s t}}{V_{J h, n}^{A C I}}$ \\
\hline 1 & $\mathrm{~J}-1$ & 217,78 & 257 & 1351,65 & 1,18 & 0,19 \\
\hline 2 & $\mathrm{~J}-2$ & 467,44 & 276 & 1351,65 & 0,59 & 0,20 \\
\hline 3 & $\mathrm{~J}-3$ & 467,44 & 286 & 1351,65 & 0,61 & 0,21 \\
\hline 4 & $\mathrm{~J}-4$ & 178,52 & 265 & 1279,80 & 1,48 & 0,21 \\
\hline 5 & $\mathrm{~J}-5$ & 277,41 & 297 & 1279,80 & 1,07 & 0,23 \\
\hline 6 & $\mathrm{~J}-6$ & 228,97 & 274 & 1334,92 & 1,20 & 0,21 \\
\hline 7 & $\mathrm{~J}-7$ & 228,97 & 219 & 1334,92 & 0,96 & 0,16 \\
\hline 8 & $\mathrm{~J}-8$ & 135,57 & 311 & 1334,92 & 2,29 & 0,23 \\
\hline 9 & $J-9$ & \begin{tabular}{|l|}
228,97 \\
\end{tabular} & 294 & 1334,92 & 1,28 & 0,22 \\
\hline 10 & $\mathrm{~J}-10$ & 229,26 & 196 & 939,14 & 0,85 & 0,21 \\
\hline 11 & $\mathrm{~J}-11$ & 204,84 & 232 & 939,14 & 1,13 & 0,25 \\
\hline & & \multicolumn{3}{|c|}{ Rata-rata } & 1,15 & 0,21 \\
\hline
\end{tabular}

Dari hasil analisa yang telah dilakukan terhadap sebelas spesiment dengan menggunakan metode Softened Strut-andTie (SST) dan metode ACI-318, maka diperoleh rasio perbandingan kuat geser $\left(\frac{V_{j h \text { test }}}{V_{J_{2}, \Omega}^{S S T}}\right)$ dengan range antara $0,59-2,29$ dengan rata-rata yang diperoleh 1,15. Sedangkan untuk $\left(\frac{V_{j h \text { test }}}{V_{j h, n}^{A C I}}\right)$ diperoleh rasio perbandingan kuat geser antara $0,16-0,25$ dengan rata-rata yang diperoleh 0,21. Untuk itu dari hasil perhitungan yang dilakukan dengan menggunakan metode Softened Strut-and-Tie maka diperoleh nilai kekuatan geser untuk setiap spesimen, dimana untuk nilai kekuatan geser pada 
spesimen J-1, J-4, J-5, J-6, J-8, J-9 dan J-11 KESIMPULAN

diperoleh nilai kekuatan gesernya lebih kecil dari hasil uji laboratorium yang telah dilakukan. Sedangkan untuk nilai kekuatan geser pada spesimen J-2, dan J-3 diperoleh nilai kekuatan gesernya lebih besar dari hasil uji lab dan untuk J-7 dan J-10 diperoleh nilai kekuatan gesernya mendekati nilai 1. Dari hasil analisis yang telah dilakukan, maka pada Gambar 4 dan Gambar 5 akan ditunjukkan grafik kekuatan gaya geser dari hasil uji lab dengan metode ACI-318 dan metode SST.

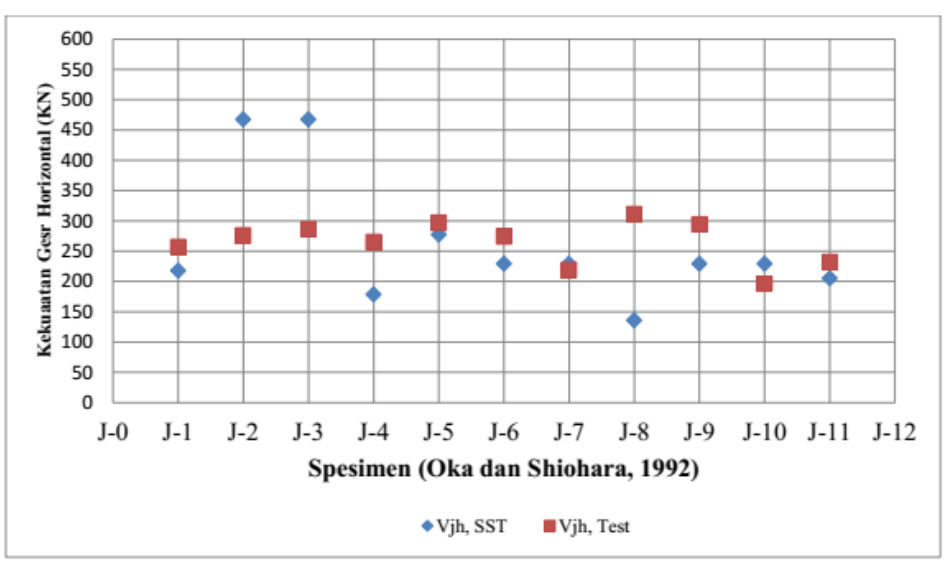

Gambar 4. Grafik kekuatan gaya geser horisontal metode Softened Strut-and Tie Model dengan hasil laboratorium

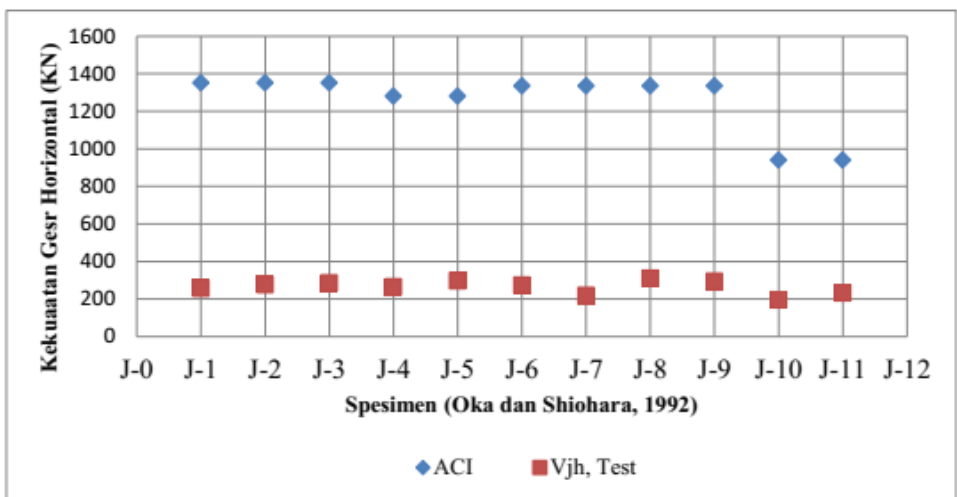

Gambar 5. Grafik kekuatan gaya geser horisontal metode Softened Strut-and Tie Model dengan hasil laboratorium
Dari hasil perhitungan yang telah dilakukan terhadap kesebelas spesimen untuk hubungan balok-kolom interior beton bertulang dengan mempergunakan metode ACI-318 dan metode Softened Strut-and-Tie (SST) maka dapat disimpulkan:

1. Nilai dari kekuatan geser yang diperoleh dengan mempergunakan metode Softened Strut-and-Tie (SST) lebih memberikan hasil yang cukup mendekati hasil uji laboratorium jika dibandingkan dengan hasil metode ACI-318. Hal ini dapat dilihat dari nilai rasio perbandingan antara hasil uji laboratorium dibandingkan dengan hasil perhitungan kedua metode tersebut.

2. Semakin tinggi nilai dari mutu beton dan mutu tulangan baja yang dipergunakan maka nilai dari kekuatan gesernya akan semakin besar juga dalam perhitungan menggunakan metode Softened Strutand-Tie (SST), sedangkan untuk metode ACI-318 yang mempengaruhi kuat gesernya adalah mutu betonnya saja.

3. Tulangan confinement yang yang berfungsi sebagai Tie ikut memberikan kontribusi terhadap nilai dari kekuatan geser yang 


\author{
dipergunakan dalam perhitungan \\ metode Softened Strut-and-Tie (SST).
}

Numerical Simulations of the bond stress-slip effect of reinforced concrete on the push over behaviour of wall. IJMERT Journal. V. 3, No. 11, November 2018. pp. 39-45.

\section{DAFTAR PUSTAKA}

ACI Committee 318, (2005). Building Code Requirements for Structural Concrete (ACI 31802) and Commentary (318R-02), American Concrete Institute, Farmington Hills, Mich. 443 pp.

Hwang, S. J. and Lee, H. J. (2000). Analytical Models for Predicting Shear Strength of Interior Reinforced Concrete Beam - Column Joints for Seismic Resistance, ACI Structural Journal. V. 97, No. 1, Jan. - Feb. 2000. pp. 35- 44.

Hwang, S. J., Lee, H. J., Liao, T.F., Wang, K.C. and Tsai, H.H. (2005). Role of Hoops on Shear Strength of Reinforced Concrete Beam-Column Joints, ACI Structural Journal. V. 97, No. 1, May - June 2005. pp. 445-453.

Hwang, S.J and H. J., Lee. (2002). Strength Prediction for Discontinuity Regions by Softened Strutand-Tie Model, Journal of Structural Engineering/December 2002/1525.

MacGregor, J and Wight, J. K. (2006), Reinforced Concrete Mechanics and Design, Singapore: Prentice Hall.

Morsch, E. (1990). Concrete steel construction, E. P. Goodrich, translator, McGraw-Hill, New York.

Oka, K and Shiohara, H. (1992). Test of high-strength concrete interior beam- column-joint subassemblages, Earthquake Engineering, Tenth World Conference@1992, Rotterdam, ISBN 9054100605.

Ritter, W. (1899). Die bauweise hennebique, Schweizerische Bauzei-tung.

Sudarno P Tampubolon. et al 2020 IOP Conf. Numerical Simulations of the bond stress-slip effect of reinforced concrete on the push over behaviour of interior beam-column joint. Ser.: Mater. Sci. Eng 725012028.

Shiohara, H. (2001). New Model For Shear Failure of $R C$ Interior Beam-Column Connections, Journal of Structural Engineering/February $2001 / 153$.

Tampubolon, S.,Wang, C.Y., Wang,R.Z., (2018). 